\title{
Action Thresholds for Summer Fungicide Sprays and Sequential Classification of Apple Scab Incidence
}

Odile Carisse, Agriculture and Agri-Food Canada, 430 Gouin Blvd., St-Jean-sur-Richelieu, Quebec, J3B 3E6, Canada; Catherine Meloche, Plant Science Department, Laval University, Quebec City, Quebec, Canada, G1K 7P4; and Guy Boivin and Tristan Jobin, Agriculture and Agri-Food Canada, 430 Gouin Blvd., St-Jean-sur-Richelieu, Quebec, J3B 3E6, Canada

\begin{abstract}
Carisse, O., Meloche, C., Boivin, G., and Jobin, T. 2009. Action thresholds for summer fungicide sprays and sequential classification of apple scab incidence. Plant Dis. 93:490-498.

The objectives of this study were to establish scab incidence thresholds at which summer fungicide sprays should be initiated and to develop sequential sampling for classification plans to facilitate decision making. The relationship between proportion of scabbed leaves per shoot and percent scabbed fruits at harvest was established based on data collected in both experimental and commercial orchards. Action threshold at which fungicide spray program should be initiated in order to maintain fruit scab at harvest below $2 \%$ was established at 0.006 scabbed leaves per shoot; hence incidence thresholds of 0.005 and 0.01 scabbed leaves per shoot were evaluated. Sequential sampling for classification procedures (SSCP), using the Wald's sequential probability ratio test (SPRT), were developed based on a beta-binomial distribution and using parameter estimates of the binary power law. Monte Carlo simulations were used to establish the probability of classifying mean scab incidence as less than the action thresholds ( $p t h=0.005$ and $p t h=$ 0.01 ). Operating characteristic (OC) and average sample number (ASN) curves were established for eight combinations of stop lines and error levels ( $\alpha$ and $\beta$ ). Based on the results of the Monte Carlo simulations, four sets of stop lines (two for each pth threshold) were selected for further evaluation. Bootstrap simulations of 50 data sets indicated that both the OC and ASN curves for each of the four pairs of stop lines were similar to OC and ASN values determined by Monte Carlo simulation. When validated with data not used to construct the models, the SSCPs provided the appropriate classification in 98 and $95 \%$ of the simulations for the $p t h=0.005$ and pth $=0.01(\alpha=0.05$ and $\beta=0.10)$, respectively. The sequential sampling plans developed in this study should allow for rapid and accurate classification of the incidence of apple scab on leaves, and aid in sampling for summer scab management decision making.
\end{abstract}

Apple scab, caused by the fungus Venturia inaequalis (Cke.) Wint., is a yearly threat to apple production in regions with cool and wet springs (12). Epidemics of apple scab develop in two phases: a monocyclic phase induced by ascospores produced in pseudothecia that overwintered in dead apple leaves, and a polycyclic phase induced by conidia. The primary infection period ends when the stock of ascospores is exhausted, which corresponds to about 2 weeks after fruit set in the northeastern United States and eastern Canada (12). Conidia are produced on primary and secondary scab lesions and serve as a source of secondary inoculum. Secondary infections progress on leaves and fruits through the summer into the autumn.

In the northeastern United States and eastern Canada, most apple scab management programs are based on an optimal

Corresponding author: O. Carisse

E-mail: carisseo@agr.gc.ca

Accepted for publication 8 January 2009.

doi:10.1094/PDIS-93-5-0490

(C) 2009 The American Phytopathological Society control of primary infections with the aim of avoiding secondary infections. Fungicide applications generally begin in spring at the bud break phenological stage and continue throughout the spring and early summer, for a total of 8 to 12 applications $(12,23)$. If fungicides have to be applied during the summer following poor control of primary infections, the annual number of fungicide sprays could rise to 14 to 16 , depending on the prevailing weather conditions during the summer months. This amount of fungicide sprays is required because commercially acceptable incidence of fruit scab at harvest is only 2 to $3 \%(5,12,23)$.

In areas where summer diseases are not a major concern, growers must decide at the end of the primary infection period if they will apply fungicides to control summer scab. In general, the decision whether or not to manage summer scab is based on their perception of their success in controlling primary scab infections. The quantitative relationship between primary scab incidence and fruit scab at harvest is not well defined $(5,6,29)$ and is difficult to establish in a quantitative manner because incidence of scabbed fruits at harvest will depend on the level of uncontrolled pri- mary infections, secondary infections that are driven by weather conditions during the summer, susceptibility of leaves and fruits to $V$. inaequalis, and fungicide sprays $(9,10,24-26)$.

Applying fungicides only when the disease has reached a specified threshold, disease incidence, or severity forms the basis of many IPM programs. The use of a threshold is more evident for decisionmaking related to fungicides including decisions on timing of applications, type of fungicide, and rate to use. Sampling procedures could be used to estimate the actual mean disease incidence or severity in a given field (16); however, to make a decision about the need to apply a fungicide, it is generally sufficient to know if the disease is below or above a specified action threshold. Action threshold is defined as the level of damage at which some action (here, applying a fungicide) must be taken to prevent an economic loss.

Sequential samplings for classification procedures (SSCPs) were developed to reduce sampling effort while maintaining reliability in estimating pest populations $(1,16,17,19)$. In agriculture, SSCPs are more commonly used to monitor insect populations $(1,19,21,22)$ than diseases $(2-$ $4,14,16,27,28,30,31)$. Sequential sampling for classification is based on a sequence of samples from a population. After each sample, a decision is made on the probability that the population mean is above or below the action threshold or if more samples are required, hence the decision can generally be taken after observation of a minimum number of samples.

The overall goal of this study was to develop sequential sampling for classification procedures for apple scab. Because the probability of making a wrong decision is mainly influenced by the action threshold (20), the first objective was to establish action thresholds for initiation of the summer fungicide spray program. The second objective was to develop sequential sampling classification models for classification of leaf scab incidence and to validate the models for their reliability in classifying scab incidences as below or above the action threshold.

\section{MATERIALS AND METHODS}

Establishment of the action threshold. Orchard sites. The data used to establish 
the action threshold were collected in experimental and commercial orchards. Orchard plots were established in 2005 and 2006 at the Agriculture and Agrifood Canada Experimental Farm in Frelighsburg, Quebec, Canada. In 2005, the experiment was conducted in a 0.62-ha orchard planted in 1984 with the scab susceptible cultivars McIntosh and Lobo grafted on M.26 rootstock planted at a distance of 5.0 $\mathrm{m}$ between rows and $2.0 \mathrm{~m}$ between trees. In 2006, the experiment was conducted in a 0.38-ha orchard planted in 1995 with the scab susceptible cultivars McIntosh and Spartan grafted on various rootstocks planted with $4.5 \mathrm{~m}$ between rows and 2.0 $\mathrm{m}$ between trees. Each year, the experimental orchard was split into four subplots of equal size (four rows of 22 trees per row, and seven rows of 15 trees per row, for 2005 and 2006, respectively). To create different levels of scab, all primary infections were controlled in one subplot; in the other three subplots, respectively, one, two, and three light to moderate infections according to the Mill's table were left uncontrolled $(13,18)$. All other primary infections were controlled with fungicide sprays, and the fungicide spray program was ended 2 weeks after petal fall; hence, summer scab was not managed. Primary infections were controlled with fungicides registered in Canada for management of apple scab: captan (80WP at 3.00 to 3.50 $\mathrm{kg} / \mathrm{ha}$ ), trifloxystrobin (50WG at 0.16 $\mathrm{kg} / \mathrm{ha}$ ), myclobutanil (40WP at 0.34 $\mathrm{kg} / \mathrm{ha})$, metiram (80DF at $6.00 \mathrm{~kg} / \mathrm{ha})$, or kresoxim-methyl (50\%WG at $0.36 \mathrm{~kg} / \mathrm{ha}$ ).

From 2004 to 2007, eight commercial orchards from the southwest and southeast regions of Quebec, Canada were selected based on cultivar susceptibility (only orchards with susceptible cultivars were selected), their expected level of primary scab infection in order to test a wide range of scab incidence, and willingness of the growers not to spray for summer scab. In each orchard, one to three orchard sections were sampled for a total of 68 data sets (not all orchards sections were assessed every year). These orchards sections were planted with cultivars McIntosh, Cortland,
Lobo, and Spartan grafted on various rootstocks.

Disease assessment. At the experimental farm, leaf and fruit scab were assessed weekly from mid-May until harvest in 2005 and from mid-June until harvest in 2006. At commercial sites, leaf scab assessments were made at the end of the primary infection period as determined by the provincial warning program, and fruit scab assessments were made at harvest. At all sites, scab was assessed on 10 trees that were randomly selected at the beginning of the season, and three terminal and three cluster shoots per tree were assessed for scabbed leaves. Fruit scab was assessed on 50 fruits chosen at random within each of the selected trees. At each sampling, the number of leaves and scabbed leaves per shoot and the number of scabbed fruits were noted.

Analysis. The data from the experimental orchard and half of the data collected in commercial orchards were used to develop the model relating leaf scab incidence at the end of the primary infection period to fruit scab incidence at harvest. The data not used for model development (34 orchard-year selected at random) were used to validate the model. Regression analysis was used to describe the relationship between proportion of scabbed leaves per shoot at the end of the primary infection period and percent scabbed fruits at harvest. Regression analysis was also used to establish the linear relationship between observed and predicted percent fruit scabbed at harvest. The regression procedure (PROC REG) of SAS (SAS V9.1, SAS Institute, Cary, NC) was used to estimate the regression parameters.

Development of the sequential sampling classification procedure (SSCP). Data collection. Data were collected from 2000 to 2006 in 13 commercial apple orchards located in the southwest and southeast regions of Quebec, Canada (Table 1). In each orchard, one to four orchard sections were sampled for a total of 155 data sets (not all orchards or orchards sections were assessed every year). Scab assessment was done within 2 weeks after the end of the primary scab period as determined by the provincial warning program Orchards were sampled in a similar way over the 7 years. Each orchard section was split into equal-size quadrats, and one tree approximately in the center of the quadrat was sampled to assure evenly spaced sampling units. The number of sampling units (trees) per orchard, $N$, was 250. Apple scab was assessed on terminal or cluster shoots selected at random within the tree. All leaves on the terminal or cluster shoots were examined for the number of scabbed leaves (average of 12 leaves per shoot). The sampling procedure could be considered as cluster sampling with $N$ sampling units of $n$ individuals (leaf) per sampling unit. The proportion of diseased leaves $(p)$ was calculated as the total number of scabbed leaves divided by the total number of leaves sampled $(n)$ per tree.

Sequential classification. The sequential sampling classification procedure (SSCP) was developed following five steps $(16,27)$ : First, we used a binary form of Taylor's power law to determine the degree of heterogeneity of leaf scab incidence for 100 data sets selected randomly within the 155 data sets collected from 2000 to 2006. Second, binomial and beta-binomial distributions were fitted to the data to determine the distribution that best represents the leaf scab incidence data. Third, the sequential probability ratio test (SPRT) following the approach developed by Wald $(1,32)$ was used to determine the stop lines for various combinations of the parameters $\alpha(0.05$ or $0.10)$ and $\beta$ (0.05 and 0.10$)$. Then best parameters of the SPRT models were determined using Monte Carlo simulations. Fourth, the SPRT models selected based on the Monte Carlo simulations were evaluated using bootstrap simulations. Finally, the SPRT models were validated with the 55 data sets not used to develop the models.

Step 1. Binary power law analysis. The binary form of Taylor's power law was used to determine the degree of heterogeneity of leaf scab incidence for the data sets used to develop the sequential classifi-

Table 1. Description of the apple orchards surveyed for apple scab caused by Venturia inaequalis

\begin{tabular}{|c|c|c|c|c|c|c|}
\hline \multicolumn{2}{|c|}{ Site } & \multirow[b]{2}{*}{ No. of data sets } & \multirow[b]{2}{*}{ Varieties } & \multirow[b]{2}{*}{ Rootstock } & \multicolumn{2}{|c|}{ Spacing (m) } \\
\hline Orchard & Region & & & & Within rows & Between rows \\
\hline 1 & Rougemont & 31 & McIntosh, Lobo & M.7 & 6.0 & 4.1 \\
\hline 2 & Franklin & 3 & McIntosh & MM.106 & 3.9 & 1.6 \\
\hline 3 & Frelighsburg & 12 & McIntosh, Cortland & Imperial & 6.7 & 4.3 \\
\hline 4 & Frelighsburg & 10 & McIntosh, Lobo & M.7 & 5.8 & 3.8 \\
\hline 5 & Frelighsburg & & McIntosh & M.7 & 6.1 & 3.9 \\
\hline 6 & Dunham & 11 & McIntosh & MM.106 & 5.0 & 3.0 \\
\hline 7 & Frelighsburg & 16 & McIntosh, Lobo & M.26 & 4.5 & 2.5 \\
\hline 8 & Rockburn & 4 & McIntosh & M.7 & 6.1 & 3.1 \\
\hline 9 & Dunham & 10 & McIntosh & MM.106 & 4.8 & 3.0 \\
\hline 10 & Rougemont & 4 & McIntosh, Lobo & M.7 & 6.1 & 0.0 \\
\hline 11 & St-Césaire & 35 & McIntosh & MM.106 & 4.9 & 3.2 \\
\hline 12 & St-Paul & 8 & McIntosh, Lobo & M.7 & 6.0 & 4.0 \\
\hline 13 & Dunham & 11 & Lobo & MM.106 & 4.7 & 2.0 \\
\hline
\end{tabular}


cation procedure $(16,27)$. The binary power law was expressed as:

$\ln \left(v_{\mathrm{obs}}\right)=\ln \left(A_{x}\right)+b \ln [n p(1-p)]$

in which $v_{\mathrm{obs}}$ is observed sample variance, $n p(1-p)$ is the binomial variance, $n$ is the number of individuals per sampling unit ( $n$ $=$ number of leaves per shoot), and $\ln \left(A_{x}\right)$ and $b$ are the intercept and slope of the regression line (15). When $A_{x}$ and $b$ are both equal to 1 , the distribution of scabbed leaves is considered to be random across all data sets (all values of $p$ ). When $b=1$ and $A_{x}>1$, the distribution of scabbed leaves is considered heterogeneous or overdispersed over the range of incidence $(p)$. When $b$ and $A_{x}$ are both greater than 1 , the distribution of scabbed leaves is con- sidered heterogeneous and heterogeneity increases with increasing $p$ up to 0.5 $(7,15)$.

Step 2. Distribution analysis. To select models for the stop lines of the SPRT, the binomial and beta-binomial discrete frequency distributions were fitted to the data for each of the 100 orchards using an SAS macro (Qi Statistics, www.qistatistes. co.uk). The binomial distribution has a single parameter, $\pi$, representing the probability of disease, while the beta-binomial distribution has two parameters: $p$, which is the expected probability of disease, and $\theta$, a measure of the variation in disease incidence among sampling units above what would be expected from a good fit to the binomial distribution. A log-likelihood
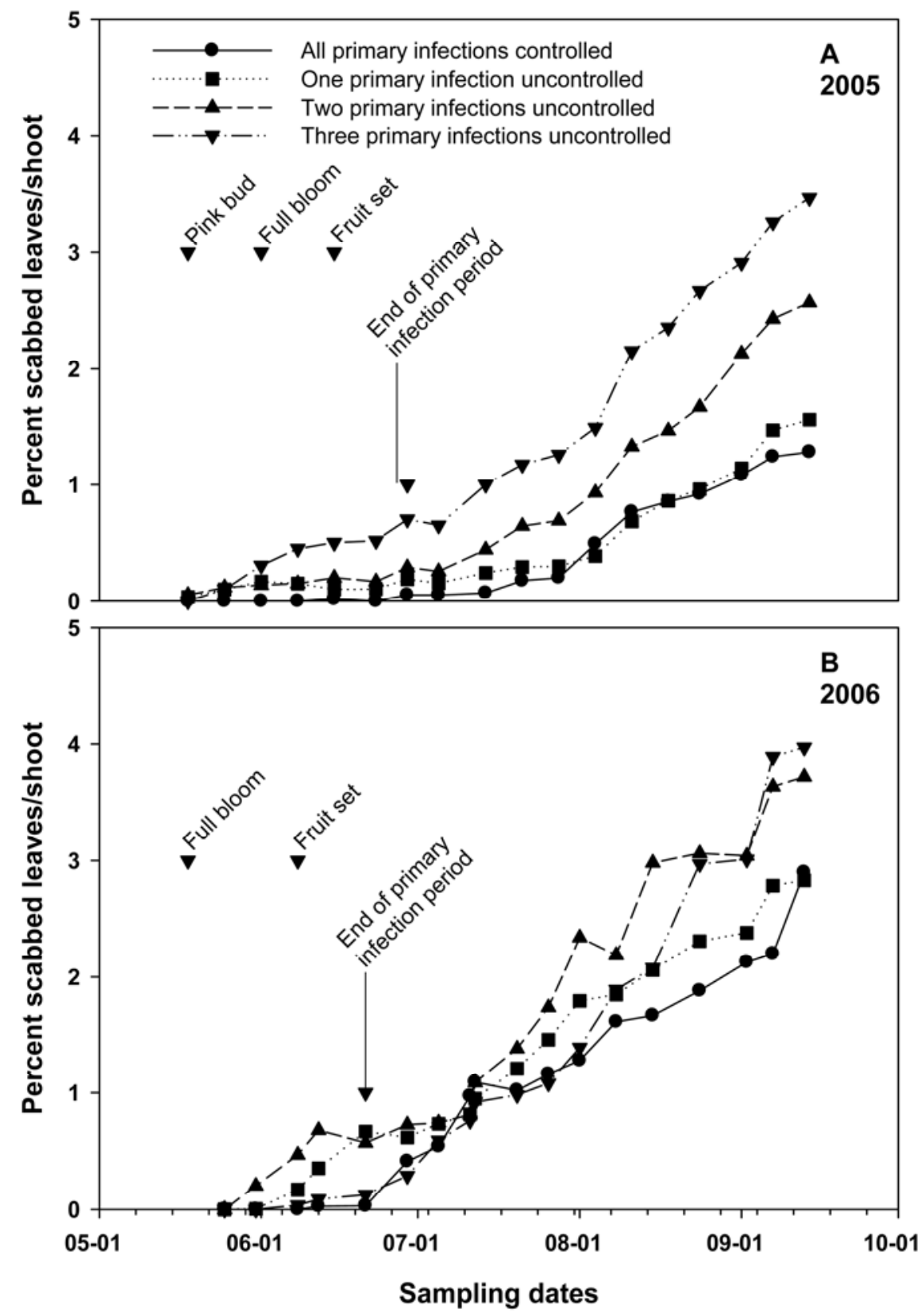

Fig. 1. Progress of leaf scab, caused by Venturia inaequalis, in orchard plots where all primary infections were controlled and one, two, and three primary infections were left uncontrolled in A, 2005 and B, 2006.

ratio test statistic was calculated to test whether the beta-binomial distribution fitted the data better than the binomial distribution.

Step 3. Sequential probability ratio test $(S P R T)$. This approach was described in details for arthropod sampling by Nyrop and Binns (19) and for plant disease sampling by Madden and Hughes (16) and by Turechek et al. (27). In an SPRT model, the null hypothesis is $H_{0}: p<p t h$ and the alternative hypothesis is $H_{1}: p>p t h$. Here, pth is the proportion of scabbed leaves per shoot at which an action such as applying a fungicide must be taken, in order to maintain the percent fruit scabbed at harvest below the economic threshold. When the null hypothesis is incorrectly rejected ( $p<$ $p t h)$, it is considered as a type I error. Similarly, when the null hypothesis is incorrectly accepted ( $p>p t h$ ), it is considered as a type II error. Operating characteristic (OC) was used to compare sequential sampling for classification models. The OC is the probability of accepting the null hypothesis, which may be a correct or incorrect decision, depending on the true value of $p$ relative to $p t h$. The $\mathrm{OC}$ is the probability of correctly accepting the null hypothesis (1-type I error) when $p<p t h$, and the probability of incorrectly accepting the null hypothesis (type II error) when $p>$ pth. In a perfect situation, the OC is 1 when $p<p t h$, and 0 when $p>p t h$. Sequential sampling classification models were also compared based on the average number of samples (ANS) required to accept or reject the null hypothesis for all values of p. Good classification models should require a small number of sampling units to make a correct decision.

Testing a hypothesis in sequential sampling for classification is more complex than accepting or rejecting $H_{0}: p<p t h$. In fact, there are three possible decisions: (1) reject $H_{0}$; (2) accept $H_{0}$; or (3) continue sampling because there is not enough information to reject or accept $H_{0}$. In SPRT, the hypothesis for the three possible decisions are: $H_{02}: p=p_{0}$, and $H_{12}: p=p_{1}$, where $p_{0}$ and $p_{1}$ are new constants such that $p_{0}<p_{1}$ and $p t h=\left(p_{0}+p_{1}\right) / 2$. Accepting $H_{02}$ could be interpreted as $p<p t h$ and accepting $H_{12}$ as $p>$ pth.

In sequential sampling for classification, two stop lines for sampling are calculated. If the cumulative number of scabbed leaves $(T N)$ is above the upper stop line, the alternative hypothesis is accepted and observed scab incidence is considered as above the action threshold ( $p>p t h)$; if the observed $T N$ is below the lower stop line, the null hypothesis is accepted and observed scab incidence is considered as below the action threshold $(p<p t h)$. Otherwise, sampling continues. Exact calculation of stop lines for an SPRT for data described by the beta-binomial distribution is not possible, but formulae approximating the stop lines have been developed 
$(16,17)$. The general formula for stop lines is:

$i_{0}+\operatorname{SnN}<T N<i_{1}+S n N$

where $S n$ is the common slope of the stop lines, and $i_{0}$ are $i_{1}$ are intercepts of the lower and upper stop lines, respectively. Intercept terms are defined in terms of A (a function of $A_{x}$ and $b$, as given in citation 16), $b, p_{0}, p_{1}$, and error parameters similar to type I $(\alpha)$ and type II $(\beta)$ errors. The general expression for the stop lines proposed by Madden and Hughes (16) for cluster sampling of incidence for the betabinomial approximation with the variance described by the binary power law (equation 1) (15) was used:

$i_{0}=\left\{\ln [\beta /(1-\alpha)] \operatorname{An}^{1-b}[p t h(1-p t h)]^{b}\right\} / p_{1}-p_{0}$

$i_{0}=\left\{\ln [(1-\beta) / \alpha] \operatorname{An}^{1-b}[p t h(1-p t h)]^{b}\right\} / p_{1}-p_{0}$

The expressions on both sides of $T N$ in equation 2 represent straight lines (stop lines) with a common slope, $S n$, and intercepts of $i_{0}$ and $i_{1}$. The slope $S$ is equal to $p t h$. The intercept terms depend on the degree of overdispersion, $p_{0}, p_{1}$, and parameters related to type I $(\alpha)$ and type II $(\beta)$ errors.

Sequential sampling classification models were designed for two incidence thresholds $(p t h), p t h=0.005\left(p_{0}=0.0025\right.$, $\left.p_{1}=0.0075\right)$ and $p t h=0.01\left(p_{0}=0.005, p_{1}\right.$ $=0.015)$, at each of the four combinations of $\alpha(0.05$ or 0.10$)$ and $\beta(0.05$ and 0.10$)$. In total, eight sequential classification models were designed and evaluated by comparing $\mathrm{OC}$ and ASN values. $\mathrm{OC}$ and ASN were calculated from Monte Carlo simulations using an Excel add-in (Poptools, version 3.0, www.cse.criso.ai. poptools). Simulations were run for 24 scab incidences ranging from 0.001 to 0.09 . The heterogeneity parameter $(\theta)$ at each value of $p$ was determined as:

$\theta=[\alpha-f(p) / n] /[f(p)-a]$

where $f(p)=[p(1-p)]^{1-b}, \alpha=A_{x} n^{b-2}$, and $A_{x}$ and $b$ are the binary power law parameters of equation 1. For each disease incidence, 100 simulations were used to establish the OC and ASN values. Based on results of the simulations, four sequential samplings for classification models, two for each threshold, were retained for evaluation and validation.

Step 4. SPRT evaluation. Bootstrapping was used to assess the variability in the selected sequential classification models over a range of values of scab incidence. Evaluation of the sequential sampling for classification models was conducted by bootstrap simulations of a subset of the 100 data sets used to develop the models and selected to cover the range of observed scab incidence. The 100 data sets were grouped in 10 categories of scab incidence ranging from $0-0.001$ to $0.009-0.010$ and from $0-0.002$ to $0.018-0.020$ to evaluate the sequential classification models for $p t h$ $=0.005$ and pth $=0.01$, respectively. Within each category, five data sets were selected for bootstrap simulation, which was repeated 100 times for each data set. For each bootstrap simulation, sampling units (one shoot $[N]$ with 12 leaves $[n]$ ) were randomly sampled, one by one, with replacement, from a record of sampling units, and the cumulative number of scabbed leaves $(T N)$ was determined.
Sampling was stopped when observed $T N$ exceeded $T N$ from the sequential classification models. The stop lines were generated by equation 2 with slope and intercept terms defined in equations 3 and 4 . In total, four sequential sampling models using the parameters $\left(p_{0}, p_{1}, \alpha\right.$, and $\left.\beta\right)$ selected based on the Monte Carlo evaluation were evaluated.

Step 5. SPRT validation data sets. Performance of the four selected sequential classification models was evaluated based

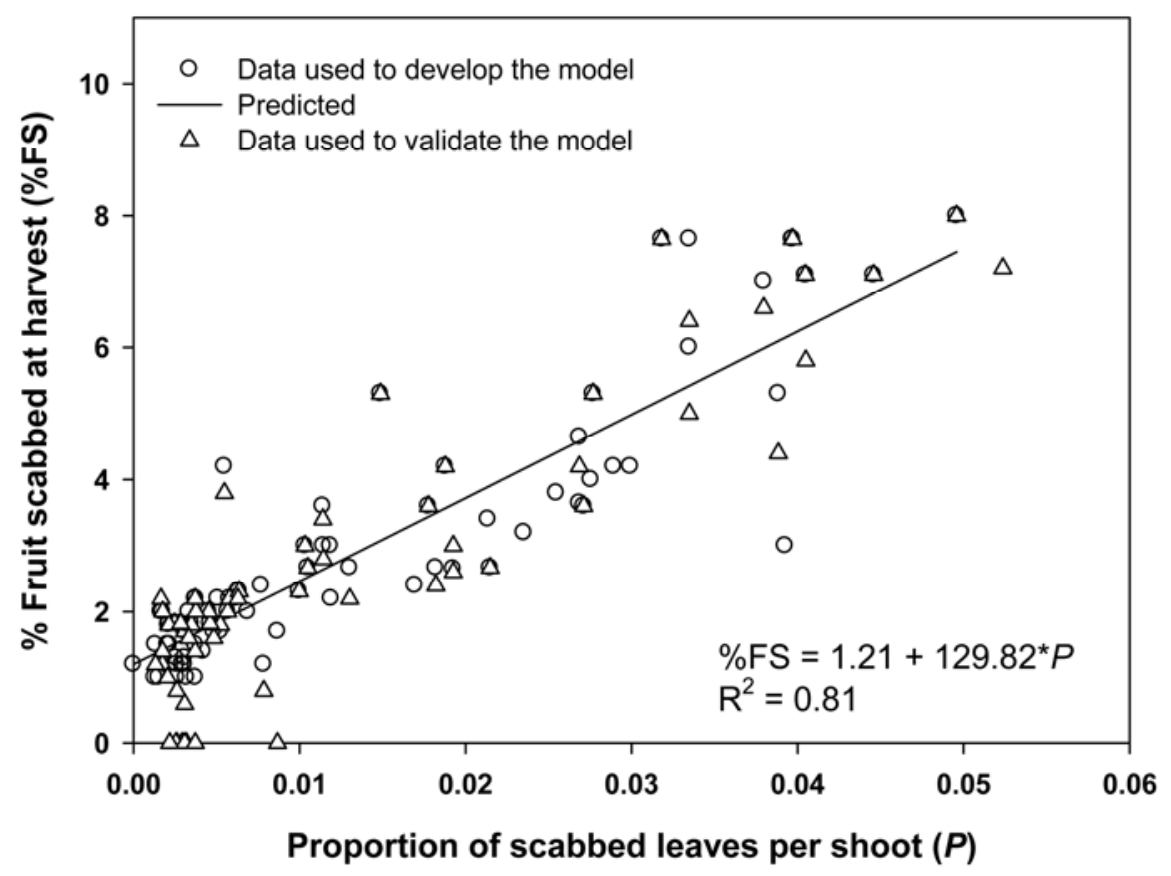

Fig. 2. Relationship between percent fruits scabbed at harvest and number of scabbed leaves per shoot at the end of the primary scab infection period in experimental and commercial orchards in Quebec, Canada.

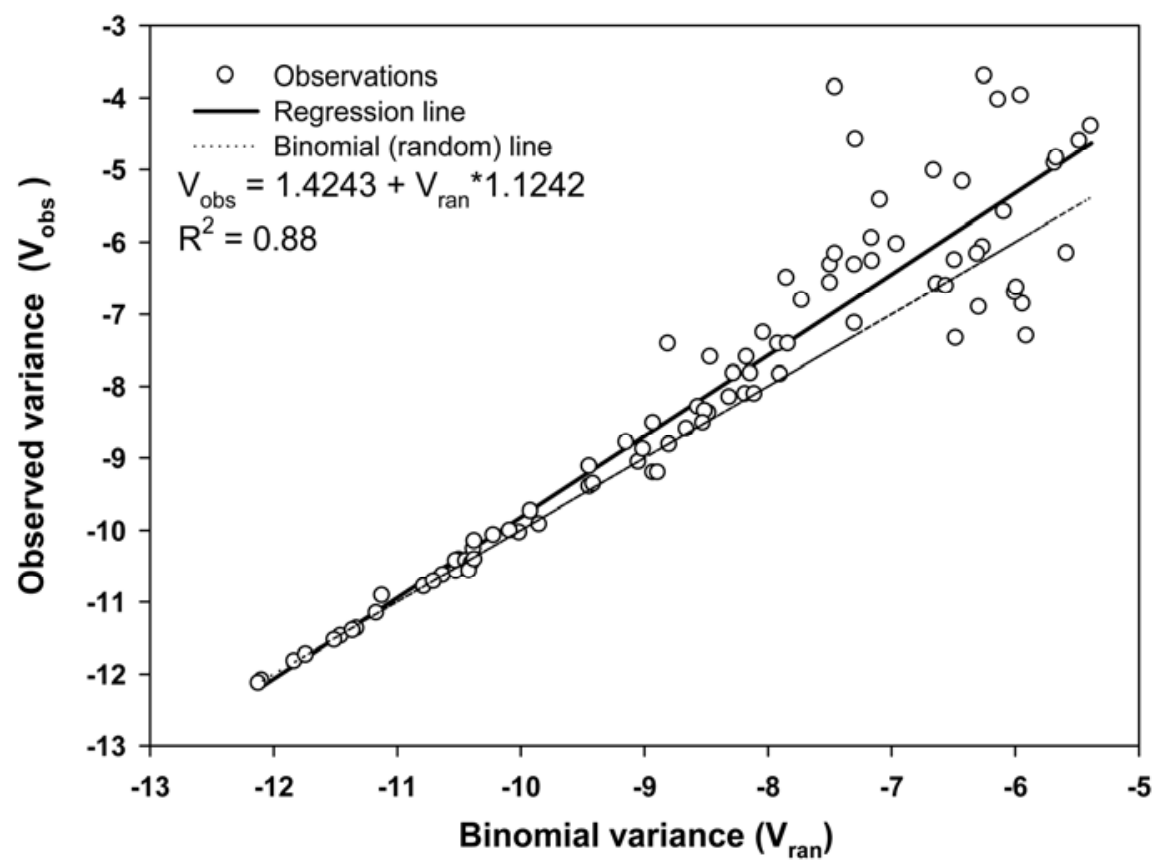

Fig. 3. Observed and fitted power-law relationships for leaf scab incidence. The dash-dot line represents the theoretical binomial line, the solid line represents the least squares regression fit to observed data. Open circles are individual values for 100 data sets. 
on resampling with replacement simulations with a program developed to run in SAS. The program randomly selected one shoot on which to begin the assessment from all possible shoots in the data set. The program continued to randomly select shoots until a total of 50 shoots had been selected. Once a set of 50 shoots was selected, the decision if the cumulative number of scabbed leaves per shoot was below or above $T N$ or if more sampling was required was made. When resampling was required, another shoot was selected. The simulations were run 100
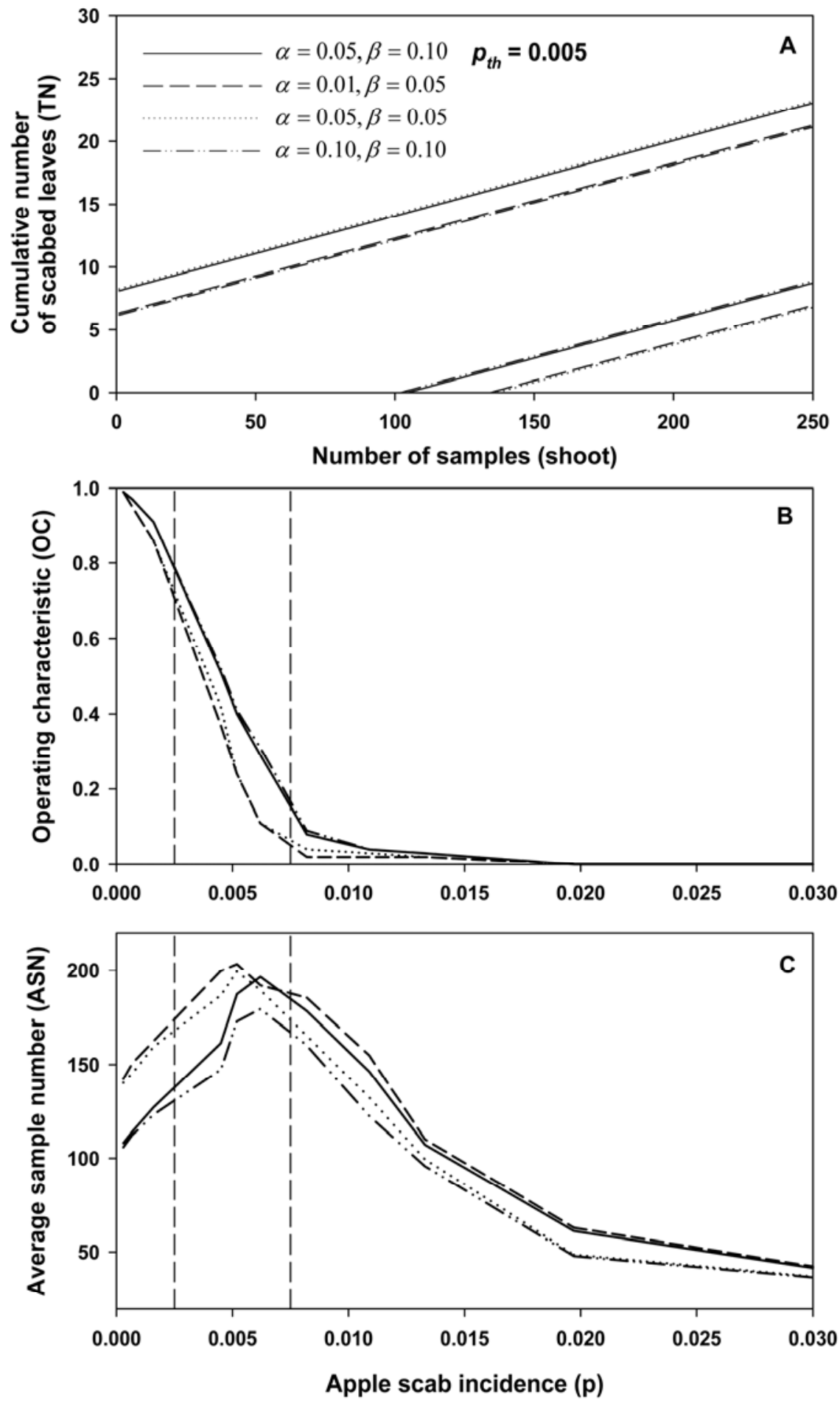

Fig. 4. A, Stop lines for cumulative number of diseased leaves $(T N)$ as a function of number of sampling units $(N)$. B, Operating characteristic (OC) curves and $\mathbf{C}$, average sample number (ASN) curves for a sequential probability ratio test of apple scab incidence from a sequential cluster sample $(n=12$ individuals per sampling unit), with parameters $p t h=0.005\left(p_{0}=0.0025, p_{1}=0.0075\right)$ at each of the four combinations of $\alpha(0.05$ or 0.10$)$ and $\beta(0.05$ and 0.10$)$. Stop lines were determined by equation 2 with slope and intercept terms given in equations 3 and 4. OC and ASN curves were determined via Monte Carlo simulation of beta-binomial distributions. Estimates of $a, A$, and $b$ are 0.50, 7.37, and 1.12 , respectively. Vertical lines represent $p_{0}$ and $p_{1}$.

times on each of the 55 data sets that were not used to develop the sequential classification models, for a total of 5,500 simulations. For each data set, we assumed that estimated $p$ for all the 250 shoots $(N)$ represented the true value of $p$ for that orchard. This true value of $p$ was compared with the hypothesized pth under evaluation to decide whether the null or alternative hypothesis was accepted. Then, the decision based on the sequential sample was compared with the assumed correct decision to determine the type I and II error rate.

\section{RESULTS}

Establishment of the action threshold. Both years, the incidence of leaf scab was lower in orchard plots where all primary infections were controlled with fungicides, and leaf scab increased when one, two, and three primary infection events were left uncontrolled (Fig. 1A and B). Within the range of scabbed leaves observed, there was a significant linear relationship between proportion of scabbed leaves per shoot at the end of the primary infection period and percent scabbed fruits at harvest (Fig. 2) in both commercial and experimental orchards. The relationship between percent scabbed fruits at harvest and proportion of scabbed leaves per shoot was linear with an intercept of $1.21(\mathrm{se}=0.12)$ and a slope of $129.82(\mathrm{se}=6.19)$ with $R^{2}=$ 0.81 . When this model was validated against data not used to develop the model, it explained $80 \%$ of the variation in percent fruit scabbed. However, to improve the robustness of the estimation of the action thresholds (proportion of leaf scab at which fungicide must be applied), a model using all data was developed. In the resulting model, the intercept and slope were 1.08 and 134.27 , and this model explained $82 \%$ of the variation in percent fruit scabbed. The predicted values of proportion of scabbed leaves per shoot for 1.5, 2, and $3 \%$ fruit scabbed were $0.003,0.006$, and 0.014 , respectively. Hence, the disease thresholds $(p t h)$ used to develop the sequential sampling for classification procedures were $p t h=0.005$ and $p t h=0.01$.

Development of the sequential sampling plan. Binary power law analysis and distribution analysis. The binary power law provided a good description of the relationship between the observed variance $\left(v_{\mathrm{obs}}\right)$ and the binomial variance $(n p(1-p))$ on a log scale (Fig. 3).

$\log \left(v_{\text {obs }}\right)=1.4243+1.1242 \log [n p(1-p)]$

The estimated intercept and slope were significantly greater than 0 and 1 , respectively $(P=0.0044$ and 0.0002$)$. Thus, there was significant overdispersion of scab incidence across all data sets, and the degree of aggregation depended on scab incidence $(b>1)$. At low variances, the points were mostly on 
or close to the line for a random distribution (Fig. 3). However, as variance increases, departure for the random line could be observed (Fig. 3). The binary power law parameters were used to calculate the stop lines of the sequential probability ratio test.

The maximum likelihood estimates of the beta-binomial parameters $p$ and $\theta$ could be calculated in $65 \%$ of the data sets, while the binomial distribution provided the best fit for only $22 \%$ of the data sets. Hence, the stop lines of the sequential probability ratio test were calculated based on the premise of a beta-binomial distribution of scab incidence.

Sequential probability ratio test (SPRT). Pairs of stop lines for the SPRT calculated from equations 2 to 4 using the slope and intercept terms from the power law analysis are shown in Figure 4A for $p t h=0.005$ and Figure 5A for $p t h=0.01$. Because of the mathematical properties of equations 3 and 4 , varying the values $\alpha$ or $\beta$ between 0.05 and 0.10 had a relatively small effect on the height of the stop lines and on the difference between the upper and lower lines within each pair (Figs. 4A and 5A). The stop lines using $\alpha=0.05$ and $\beta=0.10$ and $\alpha=\beta=0.05$ were slightly wider than the other two stop lines (Figs. 4A and 5A). Based on the Monte Carlo simulations, assuming a beta-binomial distribution, increasing the value of $\beta$ resulted in a greater rate of correct decisions (Figs. 4B and $5 \mathrm{~B}$ ) and in a slightly lower average sample number (Figs. 4C and 5C). Nevertheless, changing the values of $\alpha$ and $\beta$ had a smaller effect on ASN and OC than changing the value of $p$ th (Figs. $4 \mathrm{C}$ and $5 \mathrm{C})$. When the value of $p t h$ was changed from 0.005 to 0.01 , it resulted in a shift of the $\mathrm{OC}$ to the right and in a slight flattening of the OC at fixed values of $\alpha$ and $\beta$. This flattening is a sign of a reduction in the rate of correct decision. Furthermore, the average sample number decreased with increasing pth, and increased near pth (Figs. 4C and 5C). Based on the Monte Carlo results, the following conditions were retained for evaluation and validation: for both $p t h=0.005$ and $p t h=0.01, \alpha$ $=0.05$ and $\beta=0.10$, and $\alpha=\beta=0.10$.

Evaluation and validation of the sequential sampling classification models. Resulting OC values based on the 50 data sets randomly selected were similar to those obtained with the theoretical OC curves derived from Monte Carlo simulations at both pth values (Fig. 6). For both $p t h=$ 0.005 , the SSC models based on $\alpha=0.05$ and $\beta=0.10\left(p_{0}=0.005\right.$ and $\left.p_{1}=0.015\right)$ were slightly closer to the theoretical values of OC than the SSC models based on $\alpha$ $=\beta=0.10$ (Fig. 6A and B). However, the resulting ASN values were similar to theoretical values (Fig. 6C and D).

These results were supported by the validation of the 55 data sets not used to develop the SSC models (Table 2). Over- all, the proportion of correct decisions were slightly higher for $p t h=0.005$ than for $p t h=0.01$. For $p t h=0.005$, the proportions of correct decisions were 0.98 and 0.96 for $\alpha=0.05$ and $\beta=0.10$ and $\alpha=\beta=$ 0.10 , respectively. For $p t h=0.01$, the pro- portions of correct decisions were 0.95 and 0.93 , for $\alpha=0.05$ and $\beta=0.10$ and $\alpha=\beta$ $=0.10$, respectively. Of the incorrect decisions, type I errors were made more frequently than type II (Table 2). Mean $N$ (average sample size over the 55 data sets)
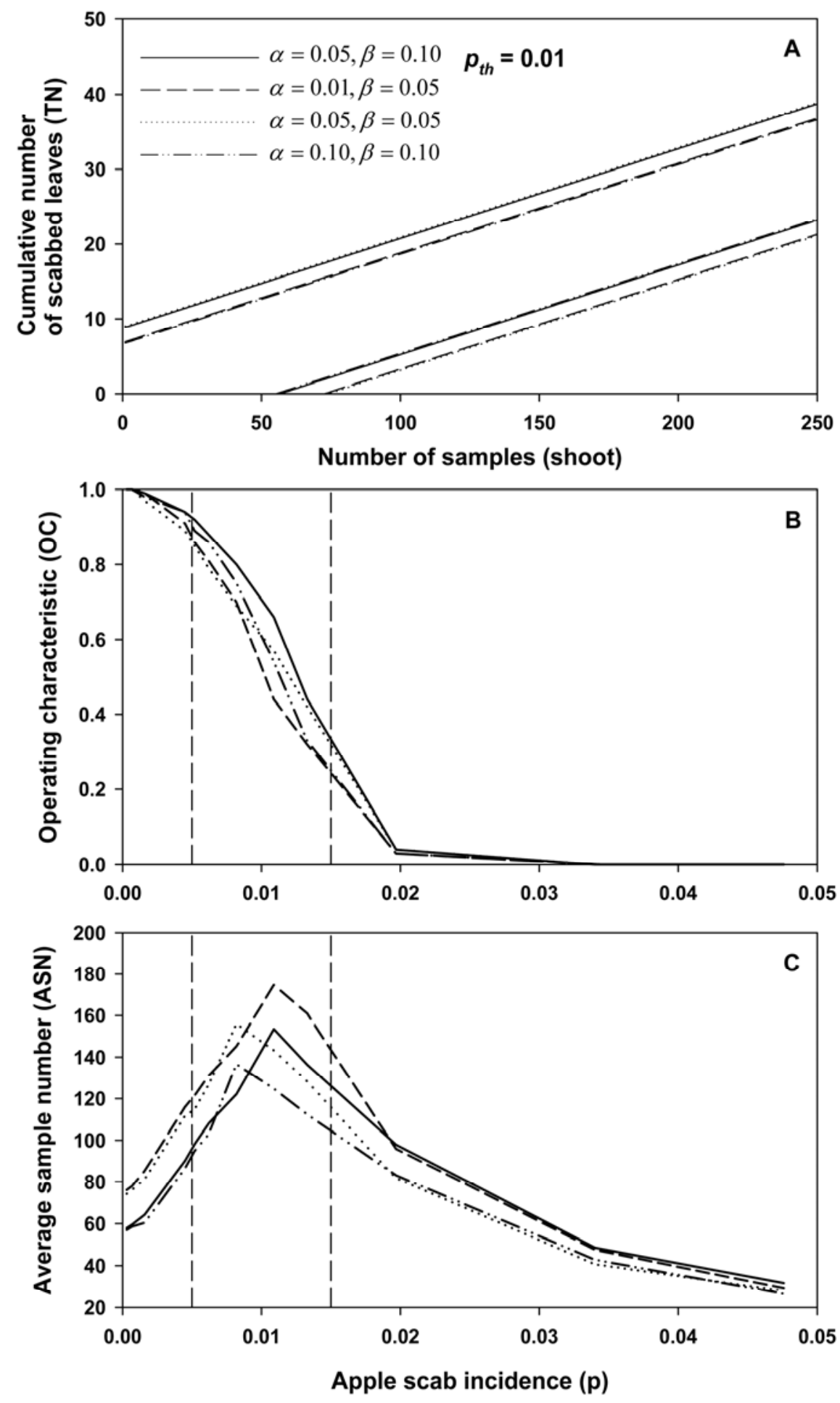

Fig. 5. A, Stop lines for cumulative number of diseased leaves $(T N)$ as a function of number of sampling units $(N)$. B, Operating characteristic (OC) curves and $\mathbf{C}$, average sample number (ASN) curves for a sequential probability ratio test of apple scab incidence from a sequential cluster sample $(n=12$ individuals per sampling unit), with parameters $p t h=0.01\left(p_{0}=0.005, p_{1}=0.015\right)$ at each of the four combinations of $\alpha(0.05$ or 0.10$)$ and $\beta(0.05$ and 0.10$)$. Stop lines were determined by equation 2 with slope and intercept terms given in equations 3 and 4. OC and ASN curves were determined via Monte Carlo simulation of beta-binomial distributions. Estimates of $a, A$, and $b$ are 0.50, 7.37, and 1.12, respectively. Vertical lines represent $p_{0}$ and $p_{1}$. 
were higher for $p t h=0.005$ than for $p t h=$ 0.01 . For $p t h=0.01$, lower number of sampling units, however, resulted in slightly lower correct decision rates (Table $2)$. From the validation process, the SSC models based on $\alpha=0.05$ and $\beta=0.10$ were retained as the best models for both $p t h$ values based on percent correct decisions, smallest type II error (accepting $H_{0}$ when $p>p t h$ ), even though slightly more samples may be required for making a decision. The final SSCP for $p t h=0.005$ and $p t h=0.01$ are presented in Figure 7A and $\mathrm{B}$, respectively.

\section{DISCUSSION}

In areas where summer diseases are not a problem and appropriate control of primary scab is achieved, it is possible to avoid applying fungicides or to reduce the number of applications during the summer months. However, at the end of the primary scab infection period, it is difficult to determine if summer fungicide sprays against apple scab are needed. Holb et al. (6) showed that summer progress of apple scab followed a logistic pattern, hence a very small amount of leaf scab at the end of spring could result in unacceptable levels of both leaf and fruit scab at harvest. Thus, it is advisable to use a conservative threshold for determining the need for summer sprays. Research has shown that early-season assessments of foliar scab correlate poorly with the incidence and severity of scabbed fruits at harvest (12). However, within the range of leaf scab incidence investigated in the present study, a linear relationship between early-season leaf scab and percent fruit scabbed at harvest was observed. Similar relationships were reported by Holb et al. (5).

Recently, Turechek and Wilcox (29) evaluated various predictors of incidence of scabbed fruits at harvest, including incidence of foliar scab and of immature fruit scab. They found that midseason immature fruit scab rating was the best predictor of fruit scab at harvest. They proposed a 7\% scab incidence on immature fruit as an action threshold to prevent fruit scab incidence at harvest exceeding $5 \%$. In practice, however, waiting until midseason to determine whether summer scab management is required might be too late for adequate management. From a grower's perspective, the decision on whether summer sprays should be initiated must be made soon after the end of the primary infection period, especially if weather is favorable to scab development. The decision to initiate or to adjust a summer fungicide spray program based on risk of fruit scab implies that the decision could be made when it is still possible to control the disease. When the decision is made early in the season, it provides enough time to control scab progress with the available fungicides (5).

Because it would not be practical to develop action thresholds and SSCPs for all possible situations including cultivar susceptibility, commercial objectives and financial situation of growers, and summer weather conditions, conservative thresholds of 0.005 and 0.01 scabbed leaves per shoot are proposed. These thresholds are close to those proposed in IPM programs
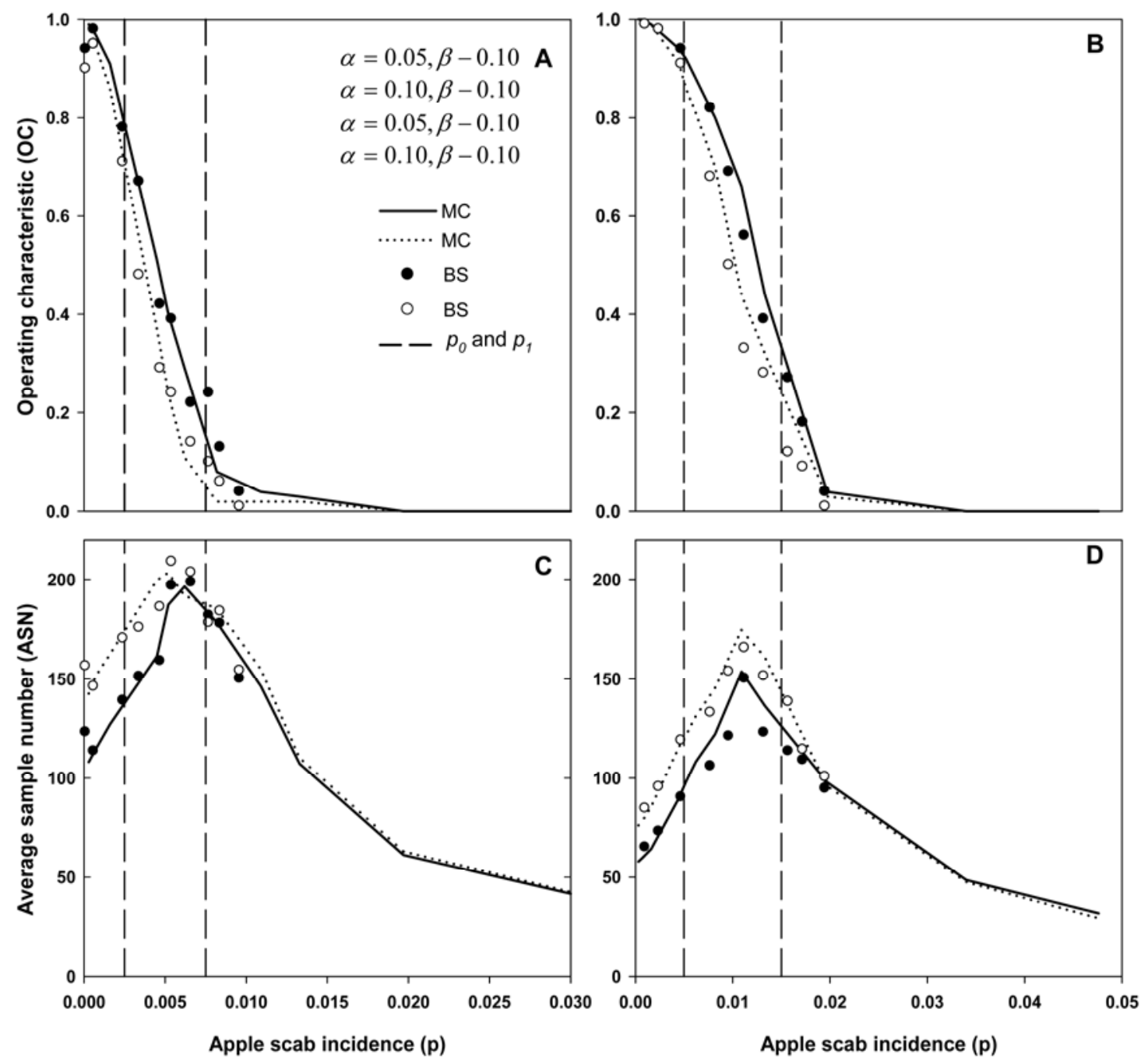

Fig. 6. A and B, Operating characteristic (OC) and $\mathbf{C}$ and $\mathbf{D}$, average sample number (ASN) curves for sequential probability ratio tests of apple scab incidence with parameters $p t h=0.005\left(p_{0}=0.003, p_{1}=0.007\right)(\mathbf{A}$ and $\mathbf{C})$ and $p t h=0.01\left(p_{0}=0.005, p_{1}=0.015\right)(\mathbf{B}$ and D). OC and ASN curves were determined via Monte Carlo (MC) simulation of beta-binomial distributions. Solid symbols represent achieved OC and ASN values from 100 bootstrap simulations (BS) of sequential sampling from 50 apple scab data sets. 
(11). In various apple growing areas, growers are advised to inspect their orchard when most ascospores have been released and all potential primary scab lesions have appeared. In general, it is recommended to look at a minimum of 100 terminal and cluster shoots per orchard block and to select at least 10 trees per block. Based on advisors and growers observations, a threshold of $0.5 \%$ (8 leaves out of 1,500 examined leaves) of leaves infested has been suggested for ending fungicide sprays (11). This threshold (11) was developed empirically; this is why the first objective of the present study was to formally establish the relationship between leaf scab at the end of the primary infection period and fruit scab at harvest.

Adjustment of a summer fungicide spray program against apple scab is also influenced by the susceptibility of developing fruit. Fruit susceptibility varies with cultivar; some cultivars, such as Jonathan and Golden Delicious, are resistant to infections that occur after fruit set (26). Fruits of the cultivar McIntosh, although less resistant, are increasingly resistant to infection from fruit set to late summer and become more susceptible to infection from late summer to harvest (26). The data used in this study were collected only on susceptible cultivars, mainly McIntosh, the leading variety grown in Quebec. Furthermore, in this study we used an economic threshold of 2 to $3 \%$ scabbed fruits at harvest, whereas Turechek and Wilcox (29) used a threshold of $5 \%$ scabbed fruits. A threshold of 2 to $3 \%$, although appropriate for the fresh market, may be too conservative for processing apples (12).

The ultimate objective of this study was to develop a scab management tool to classify orchards as above or below an action threshold, rather than to provide a precise estimation of scab incidence. From a management standpoint, it is not necessary to know the exact amount of disease present; rather, knowing whether disease exceeds the action threshold is sufficient for decision making (8). The SSCPs were validated with independent data sets (not used to develop the SSCP). For the selected SSCPs, for $p t h=0.005$ and $p t h=0.01$, the proportion of correct decisions and average sample numbers were 0.98 and $0.95 \%$ and 122 and 124 samples, respectively.

These SSCPs were developed to serve as part of an integrated apple scab management program. Ideally, starting as soon as all seasonal ascospores are ejected, each orchard block should be assessed weekly to determine whether or not it exceeds the action threshold. Because the proportion of scabbed leaves per shoot was slightly aggregated, it is advisable to select cluster and terminal shoots at random in all parts of the trees and of the orchard. Depending on weather conditions, growers could adjust the frequency of sampling. Reardon et al.
(23) tested a sequential sampling plan for autumn scab and found that it took on average $36 \mathrm{~min}$ to assess 100 shoots. Depending on mean scab incidence in the orchard, workers may be required to examine on average 82 to 84 shoots to classify the orchard using the SSCP developed here; hence sampling should take around $45 \mathrm{~min}$.

In conclusion, the SSCPs developed in this study can be used to classify orchard

Table 2. Correct decision, type I and type II errors, and mean number of sampling units for sequential probability ratio tests (SPRTs) of the incidence of apple scab caused by Venturia inaequalis in 55 commercial orchards in Quebec, Canada

\begin{tabular}{|c|c|c|c|c|}
\hline \multirow[b]{2}{*}{ Rates } & \multicolumn{2}{|c|}{$P t h=0.005$} & \multicolumn{2}{|c|}{$P t h=0.01$} \\
\hline & $\begin{array}{l}\alpha=0.05 \\
\beta=0.10\end{array}$ & $\begin{array}{l}\alpha=0.10 \\
\beta=0.10\end{array}$ & $\begin{array}{l}\alpha=0.05 \\
\beta=0.10\end{array}$ & $\begin{array}{l}\alpha=\mathbf{0 . 1 0} \\
\beta=\mathbf{0 . 1 0}\end{array}$ \\
\hline Correct decision ${ }^{\mathrm{a}}$ & 0.98 & 0.96 & 0.95 & 0.96 \\
\hline Type I error ${ }^{\mathrm{b}}$ & 0.014 & 0.032 & 0.044 & 0.042 \\
\hline Type II error ${ }^{c}$ & 0.010 & 0.012 & 0.007 & 0.027 \\
\hline Mean $N^{\mathrm{d}}$ & 124.5 & 120.7 & 121.9 & 110.1 \\
\hline
\end{tabular}

${ }^{a}$ Correct decision is percentage of orchards that were classified correctly as having a mean incidence either higher or lower than the threshold pth. It was assumed that the observed incidence for the entire data set was the true $p$.

$\mathrm{b}$ Type I error indicates that mean disease incidence was falsely declared greater than $p t h$.

c Type II error indicates that mean disease incidence was falsely declared less than $p t h$.

${ }^{\mathrm{d}}$ Mean $N$ is based on all 55 validation data sets.
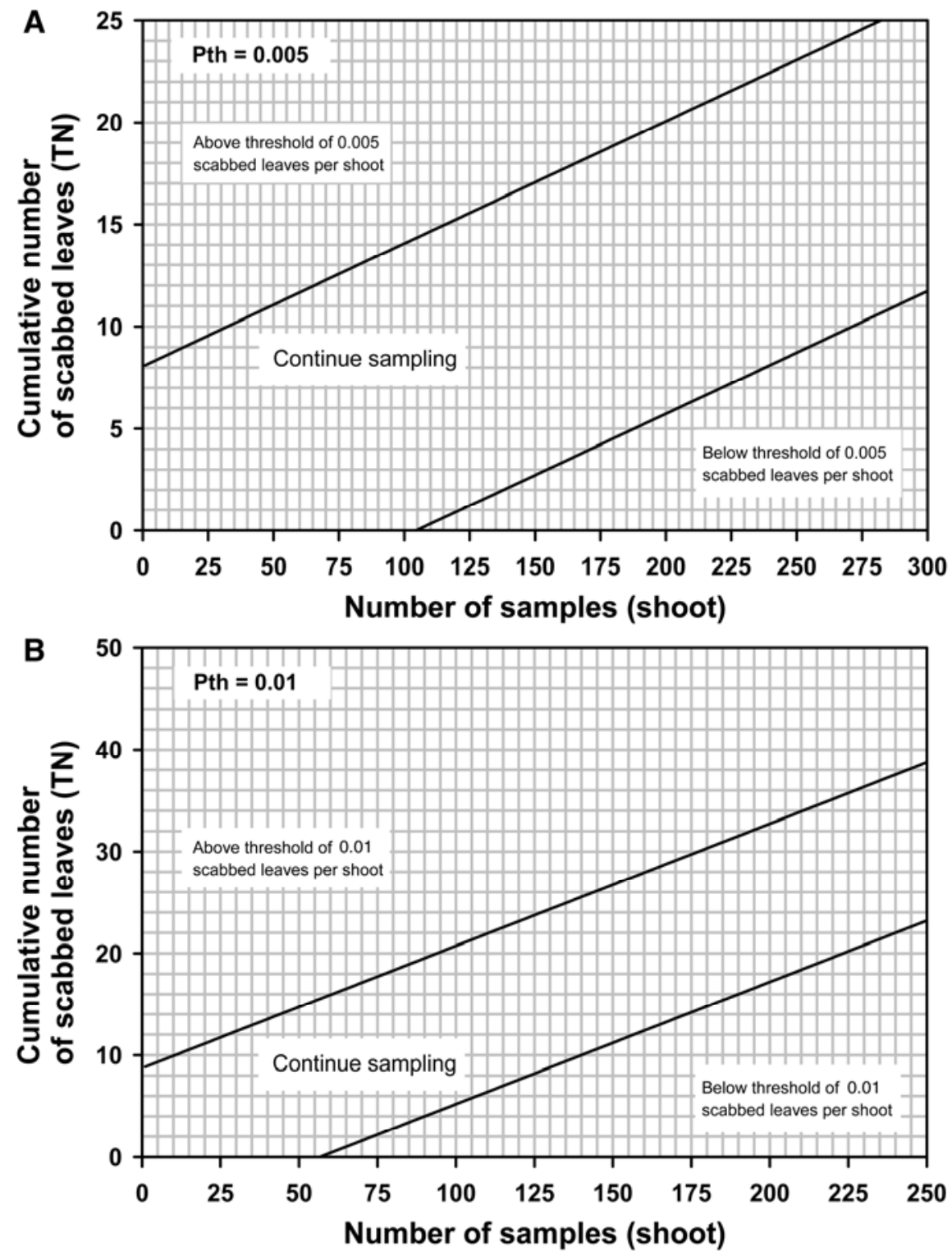

Fig. 7. Sequential sampling for classification plans for classifying scab incidence in apple orchards as above or below action thresholds of $\mathbf{A}, 0.005$ and $\mathbf{B}, 0.01$ proportions of scabbed leaves per shoot. 
blocks as above or below action thresholds of 0.005 and 0.01 scabbed leaves per shoot (Fig. 7). If the orchard block is classified as above the threshold and weather is rainy, fungicide sprays against secondary scab infections will be required. If the orchard is classified as below the threshold and weather is rainy, a second sampling should be done 1 week later to determine whether fungicide sprays are required. If the orchard is classified as above the threshold and the weather is dry, a second sampling should be done 1 week later. In this study, two action thresholds were evaluated, 0.005 and 0.01 scabbed leaves per shoot. The lowest threshold could be used as a conservative threshold and at the beginning of summer. The highest threshold could be used if more than $2 \%$ fruit scab is acceptable, the cultivar is moderately susceptible, or sampling is done later in the season. This approach, however, needs to be evaluated under field conditions and under a wide range of summer weather conditions. The SSCPs developed in this study are proposed to help growers decide when to initiate a summer fungicide spray program. In situations where primary infections were adequately controlled and the summer weather is not favorable to secondary infections, reduced fungicide spray programs will provide acceptable incidence of scabbed fruits at harvest. The use of the SSCP should minimize situations where summer fungicide spray programs are relaxed when the risk of fruit scab is high.

\section{ACKNOWLEDGMENTS}

The authors are grateful to D. Rolland, A. Lefebvre, J. F. Desteredjian, and several summer students. We thank S. Méthot from Agriculture and Agri-Food Canada for assistance in statistical analysis. This work was financially supported by a Matching Investment Initiative between Agriculture and Agri-Food Canada and the 'Fédération des Producteurs de Pommes du Québec' and a grant from the Pest Management Centre of Agriculture and Agri-Food Canada.

\section{LITERATURE CITED}

1. Binns, M. R., Nyrop, J. P., and van der Werf, W. 2000. Sampling and Monitoring in Crop Protection: The Theoretical Basis for Developing Practical Decision Guides. CABI Publishing, Wallingford, UK.
2. Boivin, G., Kushalappa, A. C., and Brodeur, L. 1990. Spatial dispersion and binomial sequential sampling plan for Cercospora carotae on carrots. J. Plant Pathol. 12:209-212.

3. Boivin, G., and Sauriol, P. 1984. Dispersion statistics and sequential sampling plan for leaf blight caused by Botrytis squamosa in onion. Phytopathology 74:1385-1387.

4. Gent, D. H., Turechek, W. W., and Mahaffee, W. F. 2007. Sequential sampling for estimation and classification of the incidence of hop powdery mildew I: Leaf sampling. Plant Dis. 91:1002-1012.

5. Holb, I. J., Heijne, B., and Jeger, M. J. 2003. Summer epidemics of apple scab: The relationship between measurements and their implications for the development of predictive models and threshold levels under different disease control regimes. J. Phytopathol. 151:335-343.

6. Holb, I. J., Heijne, B., Withagen, J. C. M., Gall, J. M., and Jeger, M. J. 2005. Analysis of summer epidemic progress of apple scab at different apple production systems in the Netherlands and Hungary. Phytopathology 95:1001-1020.

7. Hughes, G., and Madden, L. V. 1994. Aggregation and incidence of disease: Some implications for sampling. Asp. Appl. Biol. 37:25-31.

8. Hughes, G., McRoberts, N., and Burnett, F. J. 1999. Decision-making and diagnosis in disease management. Plant Pathol. 48:147-153.

9. Jeger, M. J. 1981. Disease measurement in a study of apple scab epidemics. Ann. Appl. Biol. 99:43-51

10. Jeger, M. J. 1984. Relating disease progress to cumulative numbers of trapped spores-apple powdery mildew and scab epidemics in sprayed and unsprayed orchard plots. Plant Pathol. 33:517-523.

11. Koehler, G. 2005. Apple pest reports, Integrated pest management, The University of Maine, Corporate extension, January 2006. http://pmo.umext.maine.edu/apple/AppPestRe port.html.

12. MacHardy, W. E. 1996. Apple Scab: Biology, Epidemiology, and Management. American Phytopathological Society, St.Paul, MN

13. MacHardy, W. E., and Gadoury, D. M. 1989. A revision of Mill's criteria for predicting apple scab infection periods. Phytopathology 79:304-310.

14. MacHardy, W. E., Berkett, L. R., Neefus, C. D., Gotlieb, A. R., and Sutton, D. K. 1999. An autumn foliar scab sequential sampling technique to predict the level of "scab-risk" next spring. (Abstr.) Phytopathology 89:S47.

15. Madden, L. V., and Hughes, G. 1995. Plant disease incidence: Distributions, heterogeneity, and temporal analysis. Annu. Rev. Phytopathol. 33:529-564.

16. Madden, L. V., and Hughes, G. 1999. Sampling for plant disease incidence. Phytopathol- ogy 89:1088-1103.

17. Madden, L. V., Hughes, G., and van den Bosch, F. 2007. The Study of Plant Disease Epidemics. American Phytopathological Society, St. Paul, MN

18. Mills, W. D. 1944. Efficient use of sulphur dusts and sprays during rain to control apple scab. Cornell Ext. Bull. 630:1-4.

19. Nyrop, J. P., and Binns, M. 1991. Quantitative methods for designing and analyzing sampling programs for use in pest management. Pages 67-132 in: Handbook of Pest Management in Agriculture, Vol. 2. D. Pimentel and A. A Hanson, eds. CRC Press, Boca Raton, FL.

20. Nyrop, J. P., Binns, M. R., and van der Werf, W. 1999. Sampling for IPM decision making: Where should we invest time and resources? Phytopathology 89:1104-1111.

21. O'Rourke, P. K., and Hutchison, W. D. 2003. Sequential sampling plans for estimating European corn borer (Lepidoptera: Crambidae) and corn earworm (Lepidoptera: Noctuidae) larval density in sweet corn ears. Crop Prot. 22:903-909.

22. Perry, J. N. 1994. Sampling and applied statistics for pests and diseases. Asp. Appl. Biol. 37:1-14.

23. Reardon, J. E., Berkett, L. P., Garcia, M. E., and Gotlieb, A. 2005. Field evaluation of a new sequential sampling technique for determining apple scab risk. Plant Dis. 89:228-236.

24. Schwabe, W. F. S. 1980. Wetting and temperature requirements for apple leaf infection by Venturia inaequalis in South Africa. Phytophylactica 12:69-80.

25. Schwabe, W. F. S., Jones, A. L., and Jonker, J. P. 1984. Changes in the susceptibility of developing apple fruit to Venturia inaequalis. Phytopathology 74:118-121.

26. Tomerlin, J. R., and Jones, A. L. 1983. Development of apple scab on fruit in the orchard and during cold storage. Plant Dis. 67:147-150.

27. Turechek, W. W., Ellis, M. A., and Madden, L. V. 2001. Sequential sampling for incidence of Phomopsis leaf blight of strawberry. Phytopathology 91:336-347.

28. Turechek, W. W., and Mahaffee, W. F. 2004 Spatial pattern analysis of hop powdery mildew in the Pacific Northwest: Implications for sampling. Phytopathology 94:1116-1128.

29. Turechek, W. W., and Wilcox, W. F. 2005. Evaluating predictors of apple scab with receiver operating characteristic curve analysis. Phytopathology 95:679-691.

30. van der Scheer, H. A. Th. 1987. Supervised control of scab and powdery mildew on apple. Obstbau Weinbau 24:249-251.

31. Vincelli, P. C., and Lorbeer, J. W. 1987. Sequential sampling plan for timing initial fungicide application to control Botrytis leaf blight of onion. Phytopathology 77:1301-1303.

32. Wald, A. 1947. Sequential Analysis. John Wiley \& Sons, New York. 